\title{
The end of an era and the start of something new
}

\author{
Jan Vermant ${ }^{1}$
}

Received: 29 September 2016 / Accepted: 29 September 2016 / Published online: 11 October 2016

(C) Springer-Verlag Berlin Heidelberg 2016

Prof. Henning Winter has been the editor in chief of the Rheologica Acta since 1989 (Giesekus 1989), and for more than a quarter of a century, he shouldered the weight of the journal. This exemplary service to the rheological community is now coming to an end, as Henning has decided to step down as editor in chief. Prof. Winter has made significant contributions to the field of rheology with over 200 publications. To assess his impact using the metrics of today (whether we like it or not), his papers on the use of rheology to characterize gelation are among, if not, "the" most cited rheology papers and his H-index is well over 50. Many awards recognized Prof. Winter's contributions, including the Bingham medal of the Society of Rheology in 1996. Prof. Winter is now relinquishing his position as editor in chief of the journal, but for sure will remain active in science and continue to support the journal in a new role.

Rheologica Acta first appeared as a supplement to the "Kolloid Zeitschrift" in 1958 and started appearing as an independent journal in 1963: first under the leadership of Dr. Merkat from Bayer (1958-1973) and coming to full fruition under the guidance of Prof. Hans-Werner Giesekus from 1973 to 1989. Prof. Winter joined Prof. Giesekus as co-editor in 1988 and become editor in chief in 1989. When Rheologica Acta became the Official Journal of the European Society of Rheology (ESR) in 2006, it was

Jan Vermant

jan.vermant@mat.ethz.ch

1 ETH Zürich, Department of Materials, Vladimir prelog weg 5, CH, 8093 Zuerich, Switzerland decided that the journal should add a second editor, the socalled European Editor, the first of which was Prof. Dimitris Vlassopoulos (2006-2011). In 2011, I took over the role of European Editor and continue to serve in that role. Prof. Winter's retirement from the journal is effectively the end of an era and to recognize his efforts and service to the journal and to the field we will now for the first time have an honorary editor. In his new role as Honorary Editor, Prof. Winter will assist the editors with appeal and remain an advocate for Rheologica Acta.

Aided by the editorial board we started the process of finding a new editor in chief, who will be able to strengthen the journal as it heads into the next era. We warmly welcome Prof. Lynn Walker as the new editor in chief. Prof. Walker has made significant contributions to rheology. Her research interests focus on understanding and elucidating the role of nanoscale structures on the rheology of a wide arrange of systems including liquid crystal polymers, polymer blends, surfactant mesophases, wormlike micelles, polymer-colloid solutions, and block copolymers. Recent interests focus on complex fluid-fluid interfaces and the connection between rheology and the processing of soft materials. Prof. Walker earned her Ph.D. degree in Chemical Engineering from the University of Delaware with Prof. Norm Wagner and went to another rheology stronghold for postdoctorate working with Profs. Jan Mewis and Paula Moldenaers. Prof. Lynn Walker joined Carnegie Mellon's Department of Chemical Engineering in 1997. Prof. Walker is a fellow of AIChE and has held a variety of roles in the Society of Rheology. Prof. Walker started handling manuscripts over summer.

The submission of papers to Rheologica Acta is not affected. The two editors, Lynn Walker and Jan Vermant, will 
alternate in taking responsibility in guiding your paper through the review process. Moreover, we have some great news to announce as our publisher, Springer Nature, is working to provide authors publishing in subscription journals with the ability to generate a unique shareable link (for example on your homepage) that will allow anyone to read a view-only version of the published article.
So in brief, new things are coming - please continue to submit your papers through http://mc.manuscriptcentral.com/ra/.

\section{Reference}

Giesekus H (1989) Rheologica Acta, Vol. 28, No. 1 